\title{
p38 inhibitor enhances growth inhibition and death in gallic acid-treated endothelial cells
}

\author{
YEON MI YANG ${ }^{1}$ and WOO HYUN PARK ${ }^{2}$ \\ ${ }^{1}$ Department of Pediatric Dentistry, School of Dentistry, ${ }^{2}$ Department of Physiology, Medical School, \\ Institute for Medical Sciences, Chonbuk National University, JeonJu 561-180, Republic of Korea
}

Received February 16, 2010; Accepted April 13, 2010

DOI: 10.3892/ijmm_00000465

\begin{abstract}
Gallic acid (GA) found in various plants, fruits and foods has various biological effects including apoptosis. However, little is known about the relationship between reactive oxygen species (ROS) and p38 signaling in GAtreated endothelial cells (ECs). In this study, we investigated the effects of p38 inhibitor on GA-induced calf pulmonary artery endothelial cells (CPAEC) and human umbilical vein endothelial cell (HUVEC) death in view of ROS and glutathione (GSH). GA inhibited the growth of both ECs and induced apoptosis, which was accompanied by the loss of mitochondrial membrane potential (MMP; $\Delta \Psi_{\mathrm{m}}$ ). The susceptibility of CPAEC to GA is higher than that of HUVEC. GA differently increased or decreased ROS levels in ECs. GA increased GSH depleted cell numbers in ECs. p38 inhibitor seemed to enhance cell growth inhibition and cell death in GA-treated ECs. This inhibitor increased or decreased ROS levels in GA-treated ECs. p38 inhibitor to some extent enhanced GSH depletion in GA-treated CPAEC but it clearly increased GSH depletion cell numbers in GAtreated and -untreated HUVEC. In conclusion, p38 inhibitor appeared to enhance growth inhibition and death in GAtreated ECs, which were partially influenced by the changes of ROS and GSH depletion levels.
\end{abstract}

Correspondence to: Dr Woo Hyun Park, Department of Physiology, Medical School, Institute for Medical Sciences, Chonbuk National University, JeonJu 561-180, Republic of Korea

E-mail: parkwh71@chonbuk.ac.kr

Abbreviations: GA, gallic acid; ECs, endothelial cells; CPAEC, calf pulmonary arterial endothelial cells; HUVEC, human umbilical vein endothelial cells; ROS, reactive oxygen species; MAPK, mitogen-activated protein kinase; MMP $\left(\Delta \Psi_{\mathrm{m}}\right)$, mitochondrial membrane potential; FBS, fetal bovine serum; FITC, fluorescein isothiocyanate; $\mathrm{H}_{2}$ DCFDA, 2',7'-dichlorodihydrofluorescein diacetate; DHE, dihydroethidium; GSH, glutathione; CMFDA, 5-chloromethylfluorescein diacetate; MTT, 3-(4,5-dimethylthiazol-2-yl)-2,5-diphenyltetrazolium bromide; PI, propidium iodide

Key words: gallic acid, endothelial cells, cell death, p38, reactive oxygen species

\section{Introduction}

Gallic acid (GA; 3,4,5-triphydroxyl-benzoic acid) as a polyhydroxylphenolic compound is widely distributed in various plants, fruits and foods (1) and is very well absorbed in humans (2). Various biological activities of GA have been reported, including anti-bacterial (3), anti-viral (4) and anti-inflammatory (5). The major interest in GA is related to its antitumoral activity. Anticancer activity of GA has been reported in various cancer cells, such as prostate cancer (6), lung cancer $(7,8)$, gastric, colon, breast, cervical and esophageal cancer (9). Apoptosis induced by GA is associated with oxidative stresses derived from reactive oxygen species (ROS), mitochondrial dysfunction and an increase in intracellular $\mathrm{Ca}^{2+}$ level $(10,11)$. Controversially, GA has been suggested to have both pro-oxidant and antioxidant properties depending on iron or $\mathrm{H}_{2} \mathrm{O}_{2}$ in medium and plasma $(12,13)$.

The mitogen-activated protein kinases (MAPKs) are a large family of serine/threonine kinases, which are major components of signaling pathways in cell proliferation, differentiation and cell death (14). Substantial evidence demonstrates that p38 signaling among MAPKs is involved in druginduced apoptosis and redox state changes (15-17). In addition, p38 inhibitor prevented anisomycin-induced macrophage death (18) and it decreased the death of pyrogallolinduced calf pulmonary artery endothelial cells (19). Vascular endothelium is involved in various regulatory processes such as blood pressure, inflammation and angiogenesis (20). Angiogenesis involving formation of new blood vessels from pre-existing vasculature is a crucial part of the transition of tumors from a latent to malignant state.

Despite critical roles for vascular endothelial cells (ECs) in tumor biogenesis and progression, the effects of GA on ECs remain relatively poorly understood. In addition, little is known about the relationships between ROS and p38 signaling in GA-treated ECs. Therefore, in the present study we investigated the effects of p38 inhibitor on cell growth, cell death, ROS and GSH levels in GA-treated CPAEC and HUVEC.

\section{Materials and methods}

Cell culture. CPAEC obtained from KCLB (Korean Cell Line Bank, Seoul, Korea) were maintained in humidified incubator containing $5 \% \mathrm{CO}_{2}$ at $37^{\circ} \mathrm{C}$. CPAEC were cultured 
in RPMI-1640 supplemented with $10 \%$ fetal bovine serum (FBS; Sigma-Aldrich Chemical Co., St. Louis, MO) and 1\% penicillin-streptomycin (Gibco BRL, Grand Island, NY). The primary HUVEC from PromoCell GmbH (Heidelberg, Germany) were maintained in humidified incubator containing $5 \% \mathrm{CO}_{2}$ at $37^{\circ} \mathrm{C}$. HUVEC were cultured in complete endothelial cell growth medium (ECGM, PromoCell) with $2 \%$ FBS. CPAEC and HUVEC were grown in $100-\mathrm{mm}$ plastic tissue culture dishes (Nunc). HUVEC were washed and detached with HEPES BSS (30 mM HEPES), trypsin-EDTA and trypsin neutralization solution (PromoCell). For experiments, HUVEC were used among passages four and eight.

Reagents. GA purchased from the Sigma-Aldrich Chemical Co. was dissolved in ethanol at $200 \mathrm{mM}$. p38 inhibitor (SB203580) obtained from Calbiochem (San Diego, CA) was dissolved in DMSO at $10 \mathrm{mM}$. Cells were pretreated with p38 inhibitor for $1 \mathrm{~h}$ before GA treatment. Based on previous experiments (19), $10 \mu \mathrm{M}$ of p38 inhibitor was used as an optimal dose in this experiment. Ethanol (0.2\%) and DMSO (0.3\%) were used as a control vehicle. All stock solutions were wrapped in foil and kept at $-20^{\circ} \mathrm{C}$.

Cell growth assay. The effect of GA and/or p38 inhibitor on EC growth was determined by measuring 3-(4,5-dimethylthiazol-2-yl)-2,5-diphenyltetrazolium bromide (MTT) dye absorbance of living cells as previously described (21). In brief, cells $3 \times 10^{4}$ cells per well were seeded in 96-well microtiter plates (Nunc) for MTT assays. After exposure to the indicated amounts of GA with or without p38 inhibitor for $24 \mathrm{~h}, 20 \mu \mathrm{l}$ of MTT solution ( $2 \mathrm{mg} / \mathrm{ml}$ in PBS) were added to each well of 96-well plates (Nunc). The plates were incubated for 4 additional hours at $37^{\circ} \mathrm{C}$. Medium in plates was withdrawn using pipetting and $200 \mu 1$ DMSO was added to each well to solubilize the formazan crystals. Optical density was measured at $570 \mathrm{~nm}$ using a microplate reader (Spectra MAX 340, Molecular Devices Co., Sunnyvale, CA).

Annexin V staining for cell death detection. Apoptosis was determined by staining cells with Annexin V-fluorescein isothiocyanate (FITC, PharMingen, San Diego, CA; Ex/Em = $488 \mathrm{~nm} / 519 \mathrm{~nm}$ ) and propidium iodide (PI; Sigma-Aldrich; $\mathrm{Ex} / \mathrm{Em}=488 \mathrm{~nm} / 617 \mathrm{~nm})$. In brief, $1 \times 10^{6}$ cells in $60 \mathrm{~mm}$ culture dish (Nunc) were incubated with the indicated amounts of GA with or without p38 inhibitor for $24 \mathrm{~h}$. Cells were washed twice with cold PBS and then resuspended in $500 \mu 1$ of binding buffer (10 mM HEPES/NaOH pH 7.4, $140 \mathrm{mM}$ $\left.\mathrm{NaCl}, 2.5 \mathrm{mM} \mathrm{CaCl}_{2}\right)$ at a concentration of $1 \times 10^{6}$ cells $/ \mathrm{ml}$. Five microliters of Annexin V-FITC and PI $(1 \mu \mathrm{g} / \mathrm{ml})$ were then added to these cells, which were analyzed with a FACStar flow cytometer (Becton-Dickinson).

Measurement of MMP $\left(\Delta \Psi_{m}\right)$. MMP $\left(\Delta \Psi_{\mathrm{m}}\right)$ levels were measured using rhodamine 123 fluorescent dye (SigmaAldrich Chemical Co.; Ex/Em $=485 \mathrm{~nm} / 535 \mathrm{~nm}$ ) as previously described (22). In brief, $1 \times 10^{6}$ cells in $60 \mathrm{~mm}$ culture dish (Nunc) were incubated with the indicated amounts of GA with or without p38 inhibitor for $24 \mathrm{~h}$. Cells were washed twice with PBS and incubated with rhodamine $123(0.1 \mu \mathrm{g} /$ $\mathrm{ml}$ ) at $37^{\circ} \mathrm{C}$ for $30 \mathrm{~min}$. Rhodamine 123 staining intensity was determined by flow cytometry (Becton-Dickinson). An absence of rhodamine 123 from cells indicated the loss of $\operatorname{MMP}\left(\Delta \Psi_{\mathrm{m}}\right)$ in HUVEC.

Detection of intracellular $\mathrm{ROS}$ and $\mathrm{O}_{2}^{--}$levels. Intracellular ROS such as $\mathrm{H}_{2} \mathrm{O}_{2},{ }^{\circ} \mathrm{OH}$ and $\mathrm{ONOO}^{\bullet}$ were detected by means of an oxidation-sensitive fluorescent probe dye, 2',7'-dichlorodihydrofluorescein diacetate $\left(\mathrm{H}_{2} \mathrm{DCFDA}\right.$, Invitrogen Molecular Probes, OR; Ex/Em = 495 nm/529 nm) (23). As $\mathrm{H}_{2}$ DCFDA is poorly selective for $\mathrm{O}_{2}{ }^{-}$, dihydroethidium (DHE, Invitrogen Molecular Probes; Ex/Em = $518 \mathrm{~nm} / 605 \mathrm{~nm}$ ), which is highly selective for $\mathrm{O}_{2}{ }^{-}$, was used for its detection. In brief, $1 \times 10^{6}$ cells in $60 \mathrm{~mm}$ culture dish (Nunc) were incubated with the indicated amounts of GA with or without p38 inhibitor for $24 \mathrm{~h}$. Cells were then washed in PBS and incubated with $20 \mu \mathrm{M} \mathrm{H}_{2} \mathrm{DCFDA}$ or DHE at $37^{\circ} \mathrm{C}$ for $30 \mathrm{~min}$. DCF and DHE fluorescence intensities were detected using a FACStar flow cytometer (Becton-Dickinson).

Detection of the intracellular glutathione (GSH). Cellular GSH levels were analyzed using 5-chloromethylfluorescein diacetate (CMFDA, Invitrogen Molecular Probes; Ex/Em = $522 \mathrm{~nm} / 595 \mathrm{~nm}$ ) as previously described (23). In brief, 1x $10^{6}$ cells in $60 \mathrm{~mm}$ culture dish (Nunc) were incubated with the indicated amounts of GA with or without p38 inhibitor for $24 \mathrm{~h}$. Cells were then washed with PBS and incubated with $5 \mu \mathrm{M} \mathrm{CMFDA}$ at $37^{\circ} \mathrm{C}$ for $30 \mathrm{~min}$. CMF fluorescence intensity was determined using a FACStar flow cytometer (BectonDickinson). Negative CMF staining (GSH depleted) cells were expressed as the percent of (-) CMF cells.

\section{Results}

Effects of p38 inhibitor on cell growth in GA-treated ECs. We examined the effect of p38 inhibitor on the growth of GA-treated CPAEC and HUVEC. GA dose-dependently inhibited both ECs at $24 \mathrm{~h}$ (Fig. 1). The $\mathrm{IC}_{50}$ of it in CPAEC ranged between 25 and $50 \mu \mathrm{M}$ (Fig. 1A) and that in HUVEC ranged between 200 and $400 \mu \mathrm{M}$ (Fig. 1B). p38 inhibitor slightly enhanced the growth inhibition in $5 \mu \mathrm{M}$ GA-treated CPAEC but not in $25 \mu \mathrm{M}$ GA-treated cells (Fig. 1A). In addition, p38 inhibitor mildly intensified that in GA-treated HUVEC (Fig. 1B). p38 inhibitor alone did not significantly affect the growth of either EC (Fig. 1).

Effects of p38 inhibitor on cell death and MMP $\left(\Delta \Psi_{m}\right)$ in GA-treated ECs. GA dose-dependently induced cell death in CPAEC and HUVEC, as evidenced by sub-G1 cells (data not shown) and Annexin V staining cells (Fig. 2). p38 inhibitor increased the number of Annexin V-FITC positive cells in $5 \mu \mathrm{M}$ GA-treated CPAEC. Especially, the number of Annexin V positive and PI negative (apoptotic) cells was especially increased about $10 \%$ by this inhibitor (Fig. 2A). p38 inhibitor also increased the numbers of Annexin V positive cells or Annexin V positive and PI negative (apoptotic) cells in GA-treated HUVEC (Fig. 2B). p38 inhibitor alone increased the number of Annexin $\mathrm{V}$ positive and PI negative (apoptotic) cells in control ECs (Fig. 2).

In addition, GA significantly triggered the loss of MMP $\left(\Delta \Psi_{\mathrm{m}}\right)$ in ECs (Fig. 3). GA did not dose-dependently increase 
A

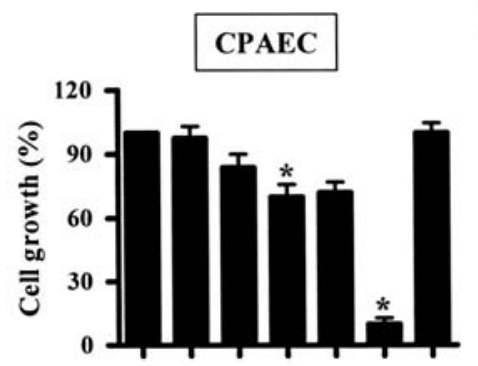

GA $\mu$ M : - 55252550 -
B

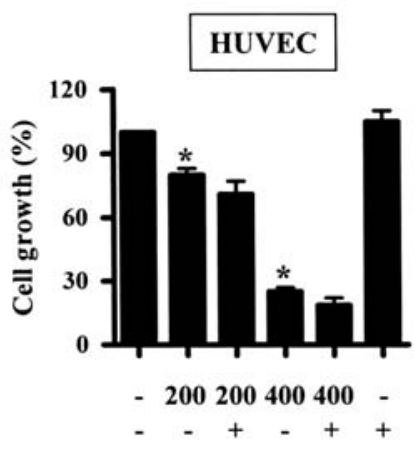

Figure 1. Effects of p38 inhibitor on cell growth in GA-treated ECs. Exponentially growing cells were treated with the indicated doses of GA for $24 \mathrm{~h}$ following $1 \mathrm{~h}$ pre-incubation of $10 \mu \mathrm{M} \mathrm{p} 38$ inhibitor. Cell growth changes in CPAEC (A) and HUVEC (B) were assessed by MTT assays. ${ }^{*} \mathrm{P}<0.05$ compared with GA-untreated control cells. The Student's t-test was used for parametric data. Statistical significance was defined as $\mathrm{P}<0.05$.

$\mathbf{A}$
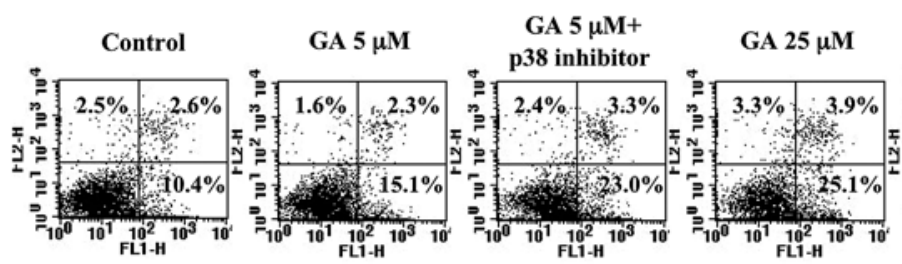

GA $25 \mu \mathrm{M}+$
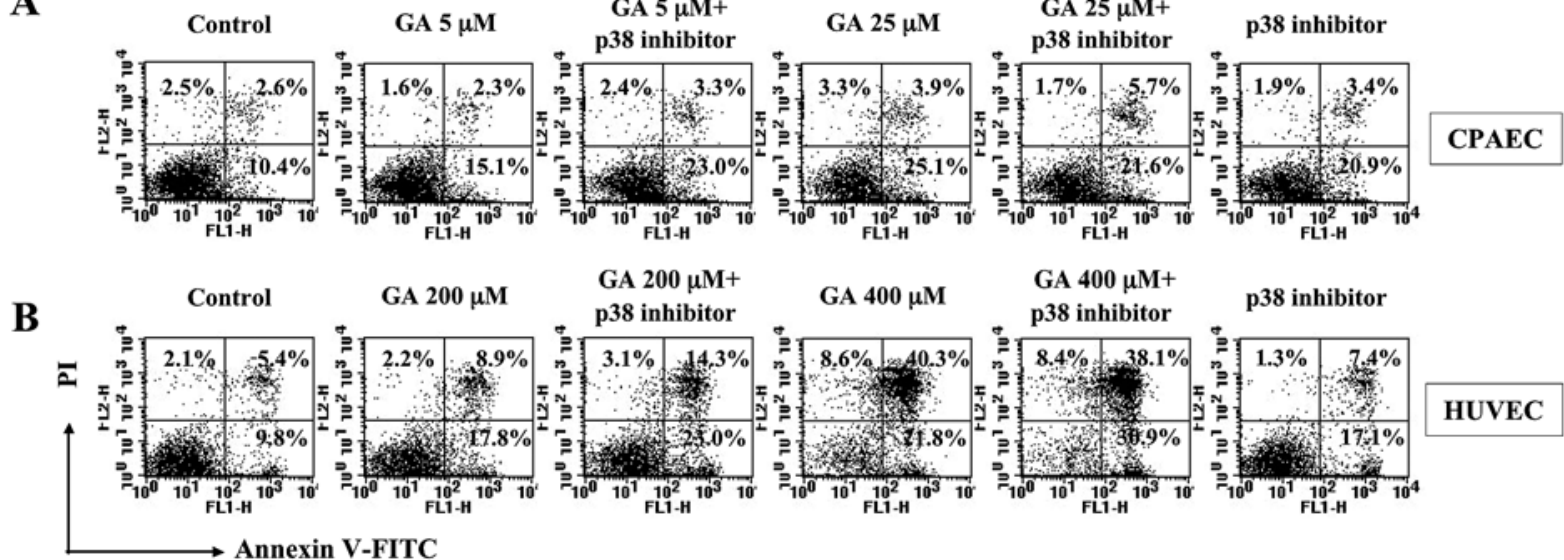

GA $200 \mu \mathrm{M}+$

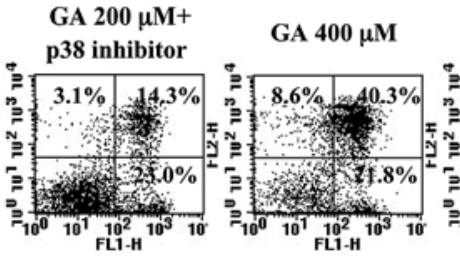

GA $400 \mu \mathrm{M}+$

p38 inhibitor

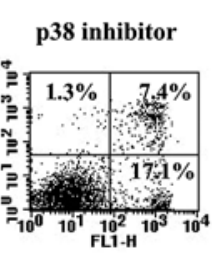

HUVEC

Figure 2. Effects of p38 inhibitor on cell death in GA-treated ECs. Exponentially growing cells were treated with the indicated doses of GA for 24 h following $1 \mathrm{~h}$ pre-incubation of $10 \mu \mathrm{M}$ p38 inhibitor. Annexin V-FITC/PI staining cells were measured with a FACStar flow cytometer. Each histogram indicates Annexin V-FITC/PI staining cells in CPAEC (A) and HUVEC (B), respectively. Viable cells were negative for both PI and Annexin V; apoptotic cells were positive for Annexin V and negative for PI, whereas late apoptotic dead cells displayed both high Annexin V and PI labeling. Non-viable cells, which underwent necrosis, were positive for PI and negative for Annexin V.

$\mathbf{A}$

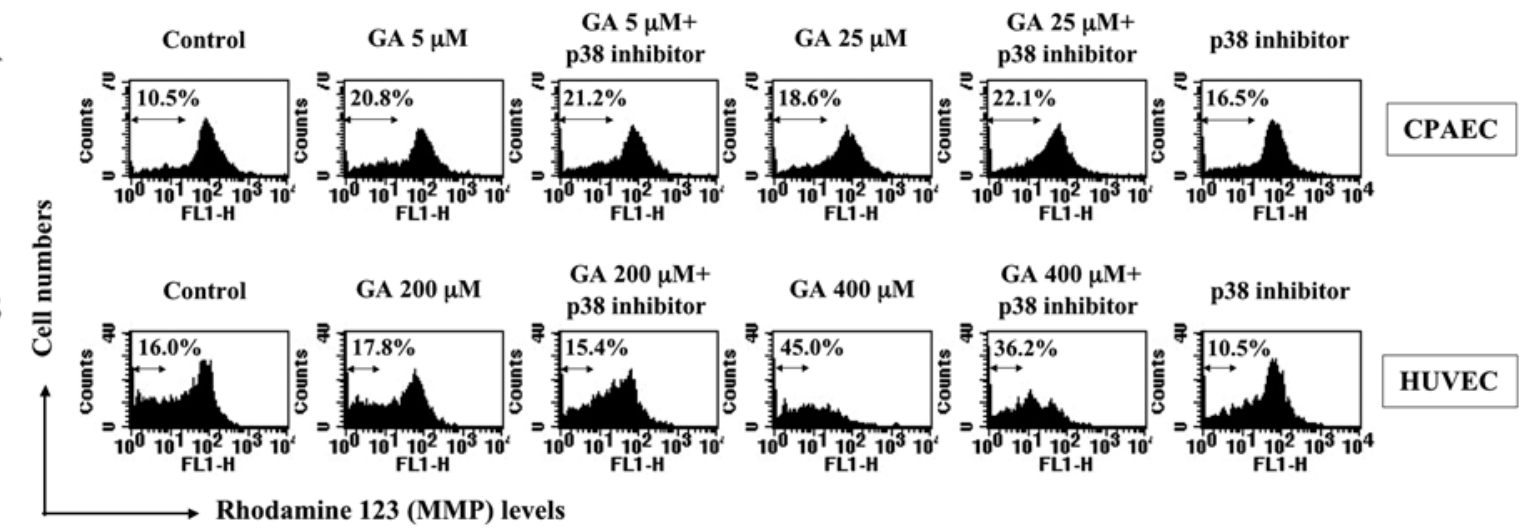

Figure 3. Effects of p38 inhibitor on MMP $\left(\Delta \Psi_{\mathrm{m}}\right)$ in GA-treated ECs. Exponentially growing cells were treated with the indicated doses of GA for $24 \mathrm{~h}$ following $1 \mathrm{~h}$ pre-incubation of $10 \mu \mathrm{M}$ p38 inhibitor. MMP $\left(\Delta \Psi_{\mathrm{m}}\right)$ in cells was measured with a FACStar flow cytometer. Each histogram indicates MMP $\left(\Delta \Psi_{\mathrm{m}}\right)$ in CPAEC (A) and HUVEC (B), respectively. The arrow marks (or percent numbers) in each histogram indicate the percent of rhodamine 123 negative $\left[\mathrm{MMP}\left(\Delta \Psi_{\mathrm{m}}\right)\right.$ loss] cells.

the loss of MMP $\left(\Delta \Psi_{\mathrm{m}}\right)$ in CPAEC but in HUVEC (Fig. 3). p38 inhibitor did not seem to affect the MMP $\left(\Delta \Psi_{\mathrm{m}}\right)$ loss in GA-treated CPAEC but slightly induced the loss of MMP
$\left(\Delta \Psi_{\mathrm{m}}\right)$ in control CPEAC (Fig. 3A). However, it slightly attenuated the MMP $\left(\Delta \Psi_{\mathrm{m}}\right)$ loss in GA-treated or -untreated HUVEC (Fig. 3B). 
A

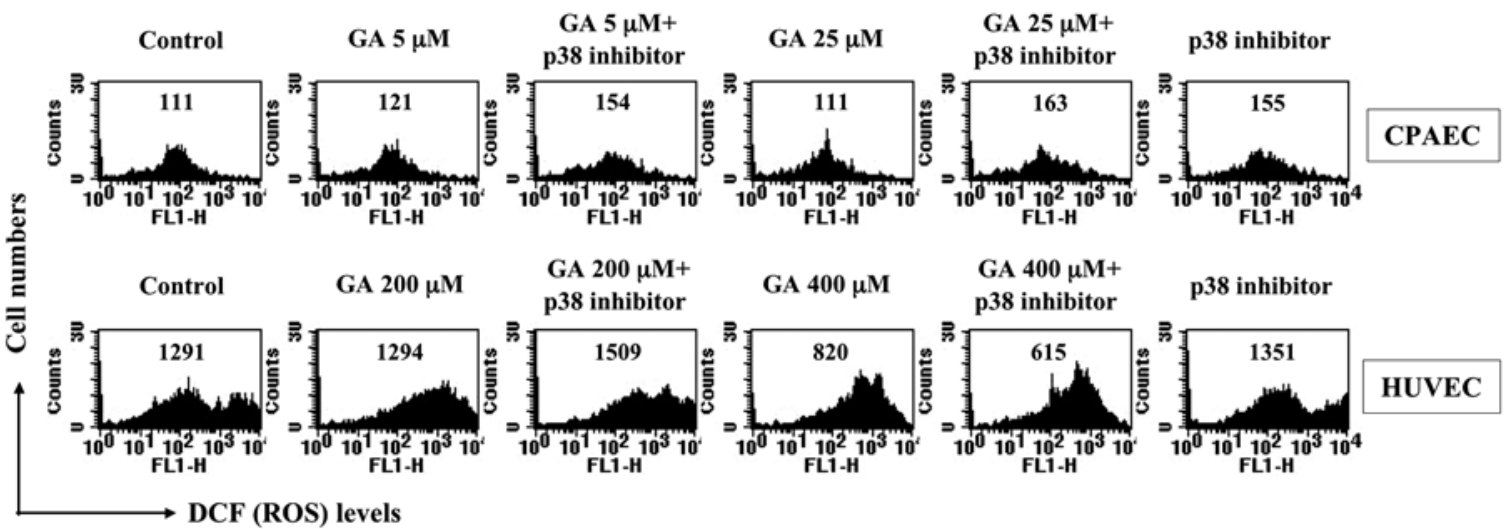

Figure 4. Effects of p38 inhibitor on DCF (ROS) levels in GA-treated ECs. Exponentially growing cells were treated with the indicated doses of GA for $24 \mathrm{~h}$ following $1 \mathrm{~h}$ pre-incubation of $10 \mu \mathrm{M} \mathrm{p} 38$ inhibitor. Each histogram indicates DCF (ROS) levels in CPAEC (A) and HUVEC (B), respectively. The numbers in each histogram indicate mean fluorescence intensity for DCF (ROS) levels.

A

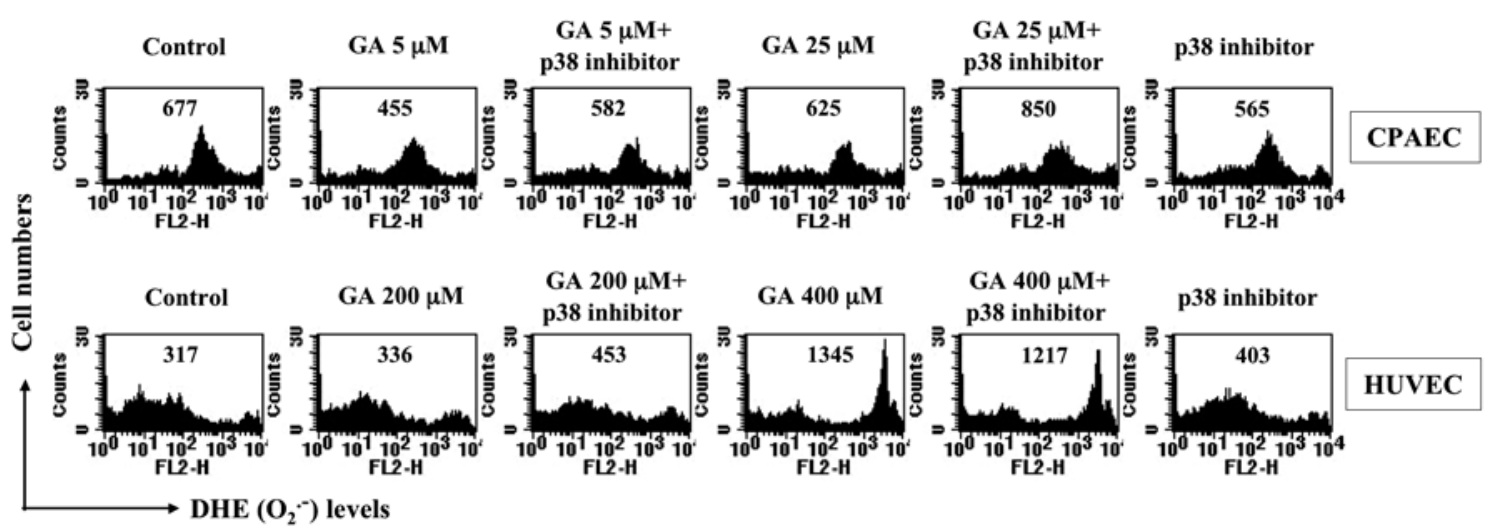

Figure 5. Effects of p38 inhibitor on DHE $\left(\mathrm{O}_{2}^{*}\right)$ levels in GA-treated ECs. Exponentially growing cells were treated with the indicated doses of GA for $24 \mathrm{~h}$ following $1 \mathrm{~h}$ pre-incubation of $10 \mu \mathrm{M} \mathrm{p} 38$ inhibitor. Each histogram indicates DHE $\left(\mathrm{O}_{2}^{\circ}\right)$ levels in CPAEC (A) and HUVEC (B), respectively. The numbers in each histogram indicate mean fluorescence intensity for DHE $\left(\mathrm{O}_{2}^{-*}\right)$ levels.

A

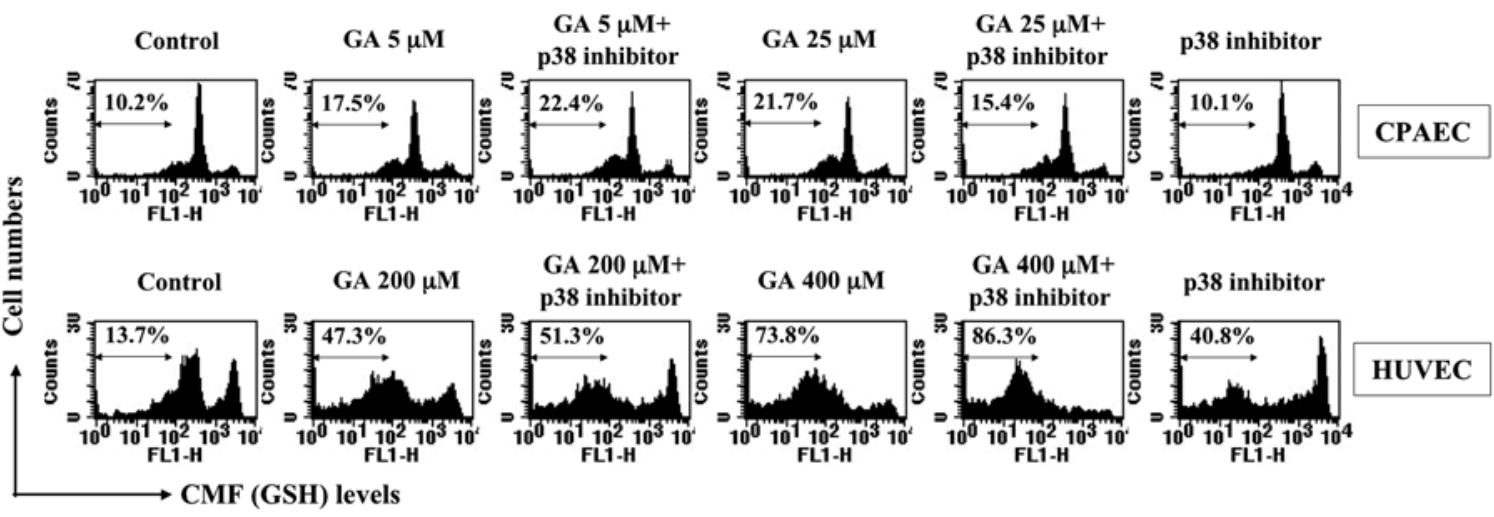

Figure 6. Effects of p38 inhibitor on GSH levels in GA-treated ECs. Exponentially growing cells were treated with the indicated doses of GA for $24 \mathrm{~h}$ following $1 \mathrm{~h}$ pre-incubation of $10 \mu \mathrm{M}$ p38 inhibitor. Each histogram indicates CMF (GSH) levels in CPAEC (A) and HUVEC (B), respectively. The arrow mark (or percent numbers) in each histogram indicate the percents of (-) CMF (GSH depleted) cells.

Effects of p38 inhibitor on ROS and GSH levels in GAtreated ECs. Next, we determined whether intracellular ROS and GSH levels in GA-treated ECs were changed by p38 inhibitor. ROS (DCF) level such as $\mathrm{H}_{2} \mathrm{O}_{2}$ was not altered in GA-treated CPAEC but was decreased in $400 \mu \mathrm{M}$ GA-treated
HUVEC (Fig. 4). p38 inhibitor seemed to increase ROS (DCF) levels in GA-treated or -untreated CPAEC (Fig. 4A). However, it increased the ROS (DCF) level of $200 \mu \mathrm{M}$ GA-treated HUVEC but decreased that of $400 \mu \mathrm{M} \mathrm{GA}$ (Fig. 4B). Red fluorescence derived from DHE reflecting intracellular $\mathrm{O}_{2}^{*}$ 
level was decreased in CPAEC treated with $5 \mu \mathrm{M}$ GA but not $25 \mu \mathrm{M}$ GA (Fig. 5A). p38 inhibitor seemed to increase $\mathrm{O}_{2}{ }^{-}$ levels in GA-treated CAPEC (Fig. 5A). GA strongly increased $\mathrm{O}_{2}^{-}$level in HUVEC treated with $400 \mu \mathrm{M}$ GA but not $200 \mu \mathrm{M}$ GA (Fig. 5B). p38 inhibitor increased $\mathrm{O}_{2}{ }^{--}$level in $200 \mu \mathrm{M}$ GA-treated HUVEC and decreased the level in $400 \mu \mathrm{M}$ GA-treated cells (Fig. 5B). This inhibitor alone decreased $\mathrm{O}_{2}^{--}$level in control CAPEC but increased that in control HUVEC (Fig. 5).

Treatment with 5-25 $\mu \mathrm{M}$ GA increased the number of GSH depleted cells about $10 \%$ in CPAEC compared with GA-untreated control cells (Fig. 6A). GA also increased GSH depleted cell number in HUVEC (Fig. 6B) and the depletion level was relatively high compared with that in GA-treated CPAEC (Fig. 6). p38 inhibitor mildly increased GSH depleted cell number in $5 \mu \mathrm{M}$ GA-treated CPAEC but decreased that in $25 \mu \mathrm{M}$ GA-treated cells (Fig. 6A). This inhibitor also increased GSH depleted cell number in GA-treated or -untreated HUVEC (Fig. 6B).

\section{Discussion}

Treatment with GA dose-dependently inhibited CPAEC and primary normal HUVEC. The $\mathrm{IC}_{50}$ in CPAEC ranged between 25 and $50 \mu \mathrm{M}$ and that in HUVEC ranged between 200 and $400 \mu \mathrm{M}$. According to our unpublished data, an $\mathrm{IC}_{50}$ of GA in human pulmonary fibroblast cells was approximately $400 \mu \mathrm{M}$ and the doses of $\mathrm{IC}_{50}$ in HeLa cervical cancer cells, Calu-6 and A549 lung cancer cells were between 30$150 \mu \mathrm{M}$. Therefore, the susceptibility of CPAEC to GA was higher than that of normal cells including HUVEC and was similar to that of cancer cells. It has been reported that GA shows lower cytotoxicity against normal fibroblast and ECs than that against cancer cells $(24,25)$. In addition, GA dosedependently increased Annexin V-FITC positive cells in CPAEC and HUVEC. The percents of Annexin V positive and PI negative (apoptotic) cells were 25.1 and $17.8 \%$ in $25 \mu \mathrm{M}$ GA-treated CPAEC and $200 \mu \mathrm{M}$ GA-treated HUVEC, respectively. These results suggest that GA-induced ECs death occurred via apoptosis. Although we do not explain the reason of these diverse susceptibilities to GA, Isuzugawa et al suggested that the different susceptibilities to GA can depend on the catalase contents of the cell (26).

It has been reported that p38 signaling among MAPKs is involved in drug-induced apoptosis and redox state changes (15-17). Furthermore, p38 inhibitor prevents anisomycininduced macrophage death (18) and it attenuates pyrogallolinduced CPAEC death (19). However, p38 inhibitor, which presumably inhibited p38 signaling, slightly enhanced growth inhibitions in GA-treated ECs. This inhibitor also increased the number of Annexin V-positive cells in these cells. Moreover, p38 inhibitor alone increased the number of Annexin V positive and PI negative (apoptotic) cells in control ECs. Therefore, the inhibition of p38 signaling by its inhibitor seemed to be a pro-apoptotic function in GA-treated or -untreated ECs.

Cell death induced by GA is associated with mitochondrial dysfunction (10). Correspondingly, GA significantly triggered the loss of MMP $\left(\Delta \Psi_{\mathrm{m}}\right)$ in ECs. However, GA did not dose- dependently increase the loss of MMP $\left(\Delta \Psi_{\mathrm{m}}\right)$ in CPAEC. The levels of MMP $\left(\Delta \Psi_{\mathrm{m}}\right)$ loss in GA-treated ECs were relatively lower than those of Annexin V-positive cells. In addition, p38 inhibitor did not affect MMP $\left(\Delta \Psi_{\mathrm{m}}\right)$ loss in GA-treated CPAEC and it reduced the loss in GA-treated HUVEC. Furthermore, p38 inhibitor alone induced MMP $\left(\Delta \Psi_{\mathrm{m}}\right)$ loss in control CPAEC but it reduced the loss in control HUVEC. Therefore, these results suggest that ECs death by GA and/ or p38 inhibitor is not tightly correlated with the loss of $\operatorname{MMP}\left(\Delta \Psi_{\mathrm{m}}\right)$. In particular, the inhibition of $\mathrm{p} 38$ seemed to be involved in mitochondrial protection in HUVEC.

GA has been reported to have both pro-oxidant and antioxidant properties $(12,13)$. Increasing evidence suggests that apoptosis induced by GA is associated with oxidative stresses derived from ROS $(11,27)$. According to our results, ROS (DCF) level such as $\mathrm{H}_{2} \mathrm{O}_{2}$ was not altered in GA-treated CPAEC and was decreased in $400 \mu \mathrm{M}$ GA-treated HUVEC. In addition, intracellular $\mathrm{O}_{2}{ }^{-}$level was decreased in CPAEC treated with $5 \mu \mathrm{M}$ GA. The $\mathrm{O}_{2}{ }^{-}$level was not changed in $200 \mu \mathrm{M}$ GA-treated HUVEC and was strongly increased in $400 \mu \mathrm{M}$ GA-treated HUVEC. These results suggest that GAinduced ECs death is not associated with oxidative stresses derived from ROS. However, we cannot exclude the possibility that GA-induced HUVEC death is related to a strong increase in $\mathrm{O}_{2}^{-}$level. p38 inhibitor seemed to increase ROS (DCF) levels in GA-treated or -untreated CPAEC. It also increased $\mathrm{O}_{2}^{-}$levels in GA-treated CPAEC. These results suggest the possibility that the enhancement of GA-induced CPAEC death by p38 inhibitor is related to an increase in ROS levels. p38 inhibitor also increased ROS levels including $\mathrm{O}_{2}^{--}$in $200 \mu \mathrm{M}$ GA-treated HUVEC. However, this inhibitor decreased the levels of $400 \mu \mathrm{M}$ GA in HUVEC, implying that the changes of ROS levels by p38 inhibitor in GA-treated HUVEC are not closely related to cell death. Taken together, GA and/or p38 inhibitor differently influence the changes of ROS levels depending on cell types.

GSH as a main non-protein antioxidant eliminates the $\mathrm{O}_{2}{ }^{-}$ and provide electrons for enzymes such as GSH peroxidase, which reduce $\mathrm{H}_{2} \mathrm{O}_{2}$ to $\mathrm{H}_{2} \mathrm{O}$. It has been reported that the intracellular GSH content has a decisive effect on anticancer drug-induced apoptosis, indicating that apoptotic effects are inversely comparative to GSH content $(28,29)$. Likewise, GA increased the number of GSH depleted cells in ECs. In addition, p38 inhibitor increased GSH depleted cell numbers in $5 \mu \mathrm{M}$ GA-treated CPAEC and GA-treated HUVEC. These results might be correlated with the results derived from Annexin V assays. However, the levels of GSH depletion in HUVEC were relatively higher than that of CPAEC (especially, in $25 \mu \mathrm{M}$ GA-treated CPEAC vs. $200 \mu \mathrm{M}$ GAtreated HUVEC). In addition, p38 inhibitor alone strongly increased GSH depleted cell number in control HUVEC. Our data suggest that intracellular GSH content is not sufficient to correctly predict cell death. The inhibition of p38 signaling seemed to be involved in GSH depletion in GA-treated or -untreated HUVEC.

In conclusion, p38 inhibitor appeared to enhance growth inhibition and death in GA-treated ECs, which were partially related to the changes of ROS and GSH depletion levels. 


\section{Acknowledgements}

This research was supported by a grant of the Korea Healthcare Technology R\&D Project, Ministry for Health, Welfare and Family Affairs and Republic of Korea (A084194).

\section{References}

1. Niemetz R and Gross GG: Enzymology of gallotannin and ellagitannin biosynthesis. Phytochemistry 66: 2001-2011, 2005 .

2. Shahrzad S, Aoyagi K, Winter A, Koyama A and Bitsch I: Pharmacokinetics of gallic acid and its relative bioavailability from tea in healthy humans. J Nutr 131: 1207-1210, 2001.

3. Kang MS, Oh JS, Kang IC, Hong SJ and Choi CH: Inhibitory effect of methyl gallate and gallic acid on oral bacteria. J Microbiol 46: 744-750, 2008.

4. Kratz JM, Andrighetti-Frohner CR, Leal PC, Nunes RJ Yunes RA, Trybala E, Bergstrom T, Barardi CR and Simoes CM: Evaluation of anti-HSV-2 activity of gallic acid and pentyl gallate. Biol Pharm Bull 31: 903-907, 2008

5. Kim SH, Jun CD, Suk K, Choi BJ, Lim H, Park S, Lee SH, Shin HY, Kim DK and Shin TY: Gallic acid inhibits histamine release and pro-inflammatory cytokine production in mast cells. Toxicol Sci 91: 123-131, 2006.

6. Kaur M, Velmurugan B, Rajamanickam S, Agarwal R and Agarwal C: Gallic acid, an active constituent of grape seed extract, exhibits anti-proliferative, pro-apoptotic and antitumorigenic effects against prostate carcinoma xenograft growth in nude mice. Pharm Res 26: 2133-2140, 2009.

7. Kawada M, Ohno Y, Ri Y, et al: Anti-tumor effect of gallic acid on LL-2 lung cancer cells transplanted in mice. Anticancer Drugs 12: 847-852, 2001.

8. Ohno Y, Fukuda K, Takemura G, et al: Induction of apoptosis by gallic acid in lung cancer cells. Anticancer Drugs 10: 845-851, 1999.

9. Faried A, Kurnia D, Faried LS, Usman N, Miyazaki T, Kato H and Kuwano H: Anticancer effects of gallic acid isolated from Indonesian herbal medicine, Phaleria macrocarpa (Scheff.) Boerl, on human cancer cell lines. Int J Oncol 30: 605-613, 2007.

10. Chen HM, Wu YC, Chia YC, Chang FR, Hsu HK, Hsieh YC, Chen CC and Yuan SS: Gallic acid, a major component of Toona sinensis leaf extracts, contains a ROS-mediated anticancer activity in human prostate cancer cells. Cancer Lett 286 : 161-171, 2009.

11. Inoue M, Sakaguchi N, Isuzugawa K, Tani H and Ogihara Y: Role of reactive oxygen species in gallic acid-induced apoptosis. Biol Pharm Bull 23: 1153-1157, 2000.

12. Strlic M, Radovic T, Kolar J and Pihlar B: Anti- and prooxidative properties of gallic acid in fenton-type systems. J Agric Food Chem 50: 6313-6317, 2002.

13. Sakagami $\mathrm{H}$ and Satoh $\mathrm{K}$ : Prooxidant action of two antioxidants: ascorbic acid and gallic acid. Anticancer Res 17: 221-224, 1997.

14. Blenis J: Signal transduction via the MAP kinases: proceed at your own RSK. Proc Natl Acad Sci USA 90: 5889-5892, 1993.
15. Repicky A, Jantova S and Cipak L: Apoptosis induced by 2acetyl-3-(6-methoxybenzothiazo)-2-yl-amino-acrylonitrile in human leukemia cells involves ROS-mitochondrial mediated death signaling and activation of p38 MAPK. Cancer Lett 277: 55-63, 2009.

16. Chowdhury R, Chowdhury S, Roychoudhury P, Mandal C and Chaudhuri K: Arsenic induced apoptosis in malignant melanoma cells is enhanced by menadione through ROS generation, p38 signaling and p53 activation. Apoptosis 14: 108-123, 2009.

17. Deng YT, Huang HC and Lin JK: Rotenone induces apoptosis in MCF-7 human breast cancer cell-mediated ROS through JNK and p38 signaling. Mol Carcinog 49: 141-151, 2009

18. Croons V, Martinet W, Herman AG, Timmermans J and De Meyer GR: The protein synthesis inhibitor anisomycin induces macrophage apoptosis in rabbit atherosclerotic plaques through p38 mitogen-activated protein kinase. J Pharmacol Exp Ther 329: 856-864, 2009.

19. Han YH, Moon HJ, You BR, Kim SZ, Kim SH and Park WH: JNK and p38 inhibitors increase and decrease apoptosis, respectively, in pyrogallol-treated calf pulmonary arterial endothelial cells. Int J Mol Med 24: 717-722, 2009.

20. Bassenge E: Endothelial function in different organs. Prog Cardiovasc Dis 39: 209-228, 1996.

21. Park WH, Seol JG, Kim ES, Hyun JM, Jung CW, Lee CC, Kim BK and Lee YY: Arsenic trioxide-mediated growth inhibition in MC/CAR myeloma cells via cell cycle arrest in association with induction of cyclin-dependent kinase inhibitor, p21 and apoptosis. Cancer Res 60: 3065-3071, 2000.

22. Han YH, Kim SZ, Kim SH and Park WH: Arsenic trioxide inhibits growth of As4.1 juxtaglomerular cells via cell cycle arrest and caspase-independent apoptosis. Am J Physiol Renal Physiol 293: F511-F520, 2007.

23. Han YH, Kim SH, Kim SZ and Park WH: Caspase inhibitor decreases apoptosis in pyrogallol-treated lung cancer Calu-6 cells via the prevention of GSH depletion. Int J Oncol 33: 1099-1105, 2008.

24. Inoue M, Suzuki R, Koide T, Sakaguchi N, Ogihara Y and Yabu Y: Antioxidant, gallic acid, induces apoptosis in HL-60RG cells. Biochem Biophys Res Commun 204: 898-904, 1994.

25. Inoue M, Suzuki R, Sakaguchi N, Li Z, Takeda T, Ogihara Y, Jiang BY and Chen Y: Selective induction of cell death in cancer cells by gallic acid. Biol Pharm Bull 18: 1526-1530, 1995.

26. Isuzugawa $\mathrm{K}$, Inoue $\mathrm{M}$ and Ogihara $\mathrm{Y}$ : Catalase contents in cells determine sensitivity to the apoptosis inducer gallic acid. Biol Pharm Bull 24: 1022-1026, 2001.

27. Serrano A, Palacios C, Roy G, Cespon C, Villar ML, Nocito M and Gonzalez-Porque P: Derivatives of gallic acid induce apoptosis in tumoral cell lines and inhibit lymphocyte proliferation. Arch Biochem Biophys 350: 49-54, 1998.

28. Poot M, Teubert H, Rabinovitch PS and Kavanagh TJ: De novo synthesis of glutathione is required for both entry into and progression through the cell cycle. J Cell Physiol 163: 555-560, 1995.

29. Schnelldorfer T, Gansauge S, Gansauge F, Schlosser S, Beger HG and Nussler AK: Glutathione depletion causes cell growth inhibition and enhanced apoptosis in pancreatic cancer cells. Cancer 89: 1440-1447, 2000. 